\title{
Influence of Rice Husk Ash on the properties of Concrete: a Review
}

\author{
Gai Fei Peng ${ }^{a}$, Juan Yang ${ }^{b}$ \\ Faculty of Civil Engineering, Beijing Jiaotong University, Beijing, china, 100044 \\ a wechio@163.com, ${ }^{\mathrm{b}}$ gfpeng@bjtu.edu.cn
}

Keywords: rice husk ash, concrete, mechanical properties, durability, workability

Abstract: Rice husk ash (RHA), produced by burning rice husk under controlled conditions, due to its high activity and high specific surface area, can be applied to concrete by replacing cement, such as in normal concrete and high-strength / high-performance concrete. In addition, its application in ultra-high strength concrete has also been reported. Many experimental studies have shown that, RHA improves the mechanical properties of concrete, decreases permeability properties and significantly ameliorates its durability. The adverse effect of reducing a slump of concrete can be resolved by increasing water reducing agent. RHA in concrete has a preferable application prospect in the future. This paper will summarize many experimental results of the application of RHA in concrete and become a reference for further research on the use of RHA in concrete.

\section{Introduction}

With the development of concrete technology, studies on highly active mineral admixtures have been gradually brought into the schedule, and silica fume (SF) has the best activity because of its mass amorphous component $\mathrm{SiO} 2$. However, the product amount generated by SF is less, collecting $\mathrm{SF}$ is more difficult and its price is higher, so that the extensive application of SF is limited [1, 2]. Accordingly, studies on seeking for a concrete additive with similar activity and physical-chemical properties as SF, as well as high output compared to SF, will be of great value [3, 4].

The rice planting area in China is huge, the yield of rice is massive, annual production of rice husk can reach up to 40 million tons [5]. Rice husk ash (RHA) obtained by burning rice husk, contains much amorphous $\mathrm{SiO}_{2}$. The amorphous $\mathrm{SiO}_{2}$ is a useful mineral admixture with the characteristics of high-activity, superfine size and ultra-large specific surface area, which are the main reason for RHA being the preferable material [6]. Accordingly, the study of the application of RHA in concrete is a sustainable development strategy, not only to utilize agricultural waste materials but also to partly reduce the use of silicate cement. Additionally, using RHA is in accordance with the new national economic development plan. In the early seventies, P. K. Mehta reported the RHA activity and its application in cement [7, 8]. Other researchers achieved similar results of RHA in cement during the same period [9-11]. Subsequently, the application of RHA in concrete as an admixture material was also reported [12-14]. In recent years, domestic and overseas scholars have conducted a great deal of experimental research on the properties of concrete incorporating RHA and achieved valuable results [15-31]. Furthermore, the results showed that high activity RHA can be used, as mineral admixture, in ultra-high strength concrete [5, 32]. It is evident that studying and developing the application of RHA in concrete has a broad prospect in the future.

\section{Effects of RHA on the Mechanical Properties of Concrete}

Research by D. Ouyang [32-34] on the quality of low-temperature RHA showed that nanoscale $\mathrm{SiO} 2$ particles and abundant pore structure in RHA contribute to the strengthening and modifying 
function of RHA in concrete. When 10 to $20 \%$ of cement was replaced by RHA, the compressive strength of concrete could be improved by more than $10 \mathrm{MPa}$. Another report indicated that with a replacement of $20 \%$, the improved strength is the most [35]. Also, the improved strength increases with the increased ratio of water to binder (w/b) [36]. In addition, both the residual compressive strength and residual elastic modulus of the RHA concrete after $500{ }^{\circ} \mathrm{C}$ and $700{ }^{\circ} \mathrm{C}$ high temperature were slightly improved compared with those of control concrete [37]. T.J. Zhao et al. found that, with a replacement of 15 to $20 \%$, the maximum improved ratio of concrete strength at 28 days is $53 \%$, while at 180 days it can reach up to $42 \%$. Thus, the low-quality RHA can still be used for high strength concrete after grinding reprocessing [15]. C.C. Guilherme also found that with the increasing dosage $f$ the low-quality RHA with high-carbon content, the improvement of concrete strength is greater. Compared with the control concrete, the compressive strength of concrete with the incorporation of $10 \%$ is hardly enhanced, and can only be slightly improved [16].

K.Ganesan et al. prepared RHA with a $\mathrm{SiO}_{2}$ content of $87 \%$ by re-combustion and investigated the effects of RHA on the mechanical properties of concrete. Their findings revealed that all specimens with a 5 to $30 \%$ addition of RHA exhibited the beneficial effect of RHA on the compressive strength and the splitting tensile strength [17]. Additionally, the research showed that, with a 7 to $15 \%$ replacement of cement, the compressive strength, the spitting tensile strength and the elastic modulus of concrete are superior to that of concrete without RHA [18]. Weerachart T. et al. found that a replacement of 20,35 or $50 \%$ by RHA enhanced the compressive strength of recycled aggregate concrete, had no effect on the splitting tensile strength, and yet it decreased the elastic modulus [19].

Application of RHA in high-strength concrete (60 MPa) was investigated by H.B. Mahmud. The reported results indicated that with $10 \%$ of RHA, whether by replacement or incorporation, the compressive strength and the splitting tensile strength were improved at all ages. Compared with the splitting tensile strength, the improved ratio of RHA to the flexure strength was greater. The improved ratio of the static modulus of elasticity was less than that of concrete strength, and was impacted by such factors as mix method, curing regime and age [20]. The results by V. Sata et al. suggested that high strength concretes with the compressive strength of $80 \mathrm{MPa}$ at 28 days, incorporating 10 to $30 \%$ RHA, exhibited higher compressive strength than the control concrete by 9 to $13 \%$. Additionally, with the $20 \%$ replacement, the compressive strength can reach up to $97 \mathrm{MPa}$ [21]. Other studies also found similar results [22, 23].

A. Salas et al. investigated the effects of RHA applied by acid treatment on high-performance concrete and found that acid treated RHA can significantly improve the compressive strength. In particular, the compressive strength and the flexure strength of high-performance concrete can be comparable to those of concrete with the same content of SF, but normal RHA failed to achieve the same desired results [24]. A. Gastaldini et al. reported that concrete incorporating RHA1 (with an average particle size of $95 \mu \mathrm{m}$ ) at the percentages of 5,10 and $15 \%$, exhibited higher compressive strength, the $10 \%$ RHA1 exhibited the best results. With the 5 and $10 \%$ mix of ultra-fine RHA2 (with an average particle size of $5 \mu \mathrm{m}$ ), the compressive strength of all concretes was enhanced at all ages, however, in the condition of $20 \%$ content, whether RHA1or RHA2, all concretes exhibited decreased compressive strength [28]. Thus, it is evident that, the particle size of RHA affects the properties of concrete. Therefore, it is very important to prepare quality RHA with the optimal particle size for further research on the application of RHA in concrete. Moreover, the compressive strength of pervious concrete with RHA was higher than that of the plain concrete, and the optimum replacement was $8 \%$. Regarding pervious concrete with fibers, the effect of RHA (at 8, 10 and 12\%) on the compressive strength and the splitting tensile strength was comparable [38]. In the range of 
5-20 wt. \% cement replacement, RHA, with the average grain size of $7.7 \mu \mathrm{m}$, effectively improved the compressive strength of self-compacting high performance concrete [39].

From the above-mentioned findings, RHA benefits the mechanical properties of concrete. The main conclusions that can be drawn are that, incorporating RHA can promote hydration, decrease the content of $\mathrm{Ca}(\mathrm{OH})_{2}$ and produce more C-S-H gel, which can lead to a densification of the concrete internal structure and the higher compressive strength [35, 36]. Another study attributed the improvement of the concrete strength to the filling effect and the active pozzolanic effect of RHA, the later one is the main factor [26].

However, a few of the experimental studies showed some adverse results. S.Q. Liang et al. found that RHA with a $78.26 \%$ content of $\mathrm{SiO}_{2}$ decreased the compressive strength, the splitting tensile strength and the flexure strength of concrete with $0.6 \mathrm{w} / \mathrm{b}$ and cement replacement with 0 to $30 \%$ RHA [40]. Another study indicated that the compressive strength of the roller compacted concrete decreased with the increasing amount of RHA [41]. Similarly, the replacement of cement with 7.5\% or $15 \%$ of the off-white RHA positively affected the compressive strength and splitting tensile strength [42]. Additionally, the compressive strength, the flexural strength and the modulus of elasticity of C40 and C50 concretes gradually decreased with the increasing dosage (from 5 to 15\%) of RHA [43]. Furthermore, the strength growth of the concrete incorporating 20\% RHA varied with the curing ages. In the short time, it was lower than that of plain concrete. However, in the long term (270 days), it was comparable to that of plain concrete [44]. Results also showed that the compressive strength and the tensile strength of concrete incorporating RHA increased with age and was lower than that of the plain concrete. However, the difference between concrete incorporating RHA and the plain concrete has been found to diminish gradually with age [45].

\section{Effects of RHA on the Durability of Concrete}

Compared with the improved ratio of RHA on the compressive strength, improving the durability of concrete has a significant better result. The reasons are concluded that RHA decreases $\mathrm{Ca}(\mathrm{OH})_{2}$ and clearly ameliorates the pore structure, a denser micro-structure can be achieved, penetrability is decreased, and accordingly a better durability is obtained. Several studies showed that, RHA noticeably improved the durability of concrete [27-29, 35].

Q.J. Yu et al. investigated the effects of RHA with varying replacement amounts of $10 \%$ and $30 \%$, on the durability of concrete by three methods, namely carbonization, hydrochloric acid corrosion and permeability test, and achieved the desired results [35]. A satisfactory result was also obtained by the air penetration test [26]. Furthermore, the electrical resistivity measurement has been applied to estimate the influencing factor of RHA on the durability of concrete [28]. K. Ganesan et al. found that compared with that of control concrete without RHA, the concrete with $30 \%$ replacement of the twice-combustion RHA, obtained by burning normal RHA again, exhibited better durability. Its water permeability was reduced by $35 \%$, the diffusion coefficient of $\mathrm{Cl}^{-}$ion was decreased by $28 \%$, and the total electric flux of $\mathrm{Cl}^{-}$ion in penetrability test was brought down by $75 \%$ [17]. With $15 \%$ RHA, the total electric flux of $\mathrm{Cl}^{-}$ion in penetrability test decreases to $576 \mathrm{C}$ in 90 days [19]. Similar results were reported in another research study [22]. Therefore, it is evident that, incorporating RHA can significantly improve the durability of concrete. Mahmud H.B et al. also reported that RHA remarkably increased the durability of high-strength concrete [25]. Superior durability of high-performance concrete with the addition of $20 \%$ RHA was also reported by C.C .Guilherme. The studies on the durability of high-strength/high-performance concrete incorporating RHA have reported similar results [20, 24]. Apart from the above-mentioned methods, the rapid-freezing and thawing test can be used to investigate the effects of RHA on the durability 
of concrete $[22,30]$.A study by Q.G. Feng showed that, when the content of RHA was $10 \%$ and $20 \%$, concretes with the w/b of $0.45,0.55$ and 0.65 exhibited better freezing and thawing-resistance performance [30]. In a different study, M.H. Zhang, et al. also reported that RHA exhibited a better resistance performance to freezing-thawing and de-icing salt [22]. D. Ouyang reported that RHA reduced the content of $\mathrm{Ca}(\mathrm{OH})_{2}$ in the interface of the reinforcement and concrete and decreased the crystal orientation of $\mathrm{Ca}(\mathrm{OH})_{2}$ in the interface. Also, RHA improved the bond strength of the steel bar and enhanced the durability of the reinforced concrete structure [31].

Moreover, above all, RHA with high-activity not only enhances the mechanical properties of concrete, but also significantly improves the durability of concrete. Furthermore, incorporating RHA can decrease the autogenously shrinkage of concrete $[20,22,46]$ and the replacement of $20 \%$ of cement by RHA displayed a positive effect on the resistance to $\mathrm{HCl}$ and $\mathrm{H}_{2} \mathrm{SO}_{4}$ attacks [46]. Similar result was reported for the self-compacted concrete incorporating RHA with the replacement of $25 \%$ and $20 \%$ [47]. However, the depth of carbonation of concrete incorporating RHA was higher than that of plain concrete and the replacement of $40 \%$ of cement by RHA impaired the resistance to $\mathrm{H}_{2} \mathrm{SO}_{4}$ attack [46]. In addition, incorporating $15 \%$ of untreated RHA could almost double the carbonation depth, because RHA consumed $\mathrm{Ca}(\mathrm{OH})_{2}$ and the secondary hydration of RHA was lower [48].

\section{Effects of RHA on the Workability of Concrete}

High activity RHA enhances the mechanical properties of concrete and remarkably improves the durability. However, RHA decreases the workability of concrete. Many studies have showed that RHA increases the water usage of concrete and the water reducing agent for designed slumps because of its abundant pores and ultra-high specific surface area, which significantly affects the workability of concrete [19,24,30,49-51]. RHA raises the dosage of water reducer and will influence the extensive application of RHA because of economic efficiency [27]. W. Tangchirapat reported that concrete incorporating RHA needed a mass of water reducer. For the 50-100 mm slumps, when RHA replaced cement by $20 \%$ or $30 \%$, the amount of water reducing agent needed was $1.7 \mathrm{~kg} / \mathrm{m}^{3}$, which increased to $3.3 \mathrm{~kg} / \mathrm{m}^{3}$ when it was $50 \%$ [19]. C.C Guillermo et al. reported that with the $10 \%, 15 \%$ and $20 \%$ content of RHA, the $130 \mathrm{~mm}$ slumps of concrete decreased to 100 $\mathrm{mm}, 60 \mathrm{~mm}$ and $20 \mathrm{~mm}$, respectively. Thus, increasing the dosage of water reducer is a necessary measure to improve the workability of concrete [16]. D. Ouyang reported that RHA has a water-increasing function. The water reducer hardly affects the water demand of the RHA concrete, because the vast majority of RHA surface area is the internal surface of the pore, whereas water reducing agent can only efficiently work on the water adsorbed in the outside surface [49-51]. Additionally, the slumps of high-strength concrete incorporating RHA with the replacement of $5-20 \%$ were higher than that of concrete adding SF with the same dosage. While, when the replacement was $25 \%$ and $30 \%$, the result was adverse [52].

According to the above results, incorporating RHA in concrete increases the water demand, decreases the slump of concrete and has a negative influence on the workability of concrete. Therefore, the application of RHA in concrete, especially which at a lower w/b, must take the necessary measures to assure the good workability of concrete, namely using large amounts of water reducing agent. However, the dosage of water reducing agent was restricted to be lower than its saturation dosage to avoid its segregation. Accordingly, the RHA content was influenced by the performance of water reducing agent. The reported results indicated that the dosage of water reducing agent should be between $70-80 \%$ of its saturation dosage to prepare the self-compacting concrete and the RHA content greater than $15 \%$ replacement of the binder was not suitable [53]. 
A very important point to note is that the RHA obtained by burning rice husk can be burnt again and exhibits a better performance with higher $\mathrm{SiO}_{2}$ [54], because the $\mathrm{SiO}_{2}$ brings about beneficial influence on the properties of the concrete [17]. A study showed that RHA can be used to produce ultra-high-performance concrete (UHPC) with the compressive strength of over $150 \mathrm{MPa}$, and its contribution on the compressive strength of UHPC was superior to that of silica fume [55]. In addition, research on hydration and microstructure of the ultra-high-performance concrete incorporating RHA was also carried out [56].

\section{Conclusions and Further Research Needed}

As a high-active pozzolanic admixture, RHA can improve the mechanical properties of concrete, ameliorates the durability of concrete, and can be comparable to SF and can be applied to concrete as a mineral admixture. Its adverse influence on the workability of concrete can be resolved by increasing the dosage of water reducing agent within its saturation dosage. Therefore, the application of RHA in concrete has a preferable developing prospect in the future.

However, for the extensive application of RHA, its contribution to the development of concrete materials and meeting the low-carbon life greatly promoted in society, further research of RHA is needed, as follows:

(1) It is very important to prepare superior quality RHA with high quantity. However, according to currently available combustion equipment and technology, it is difficult to singly produce high quantity RHA under the proper control conditions. Thus, related new technology is needed.

(2) Many researchers pay a close attention to environmental-friendly concrete materials. RHA, as a high active pozzolanic admixture, whether it can be used in many types of concrete or not need further experimental investigations.

(3) Various combustion conditions significantly affect the components of RHA. RHA, obtained by burning rice husk, and then is burnt again, even for more times, how is its application in concrete? If concrete incorporating RHA is exposed to high temperature, research on the residual performance of the RHA concrete and whether RHA can resist high temperature or not is needed.

\section{Acknowledgements}

This work was financially supported by the financial support of the National Science Foundation of China (51278048, 51078030).

\section{References}

[1] W.N. Yan, C. Wang. China Concrete and Cement Products, (6), (1998).

[2] K.F. Tan, X.C. Pu. China Concrete and Cement Products, (1), (1998), p. 11-12.

[3] D. OuYang. China Building Materials, (6), (2003), p. 42-46.

[4] X.G. Cai. Journal of Guangxi Academy of sciences, 15 (4), (1999), p.190-195.

[5] D. Ou Yang. Guangzhou: South China University of Technology (1997).

[6] S. Chandrasekhar et al. Journal of materials science, 38(2003), p. 3159-3268.

[7] P.K. Mehta. Journal Proceedings, ACI (1977).

[8] P.K. Mehta. Proc. on Rice Husk Ash Cement, Peshawar, Pakistan, (1979), p.113-122.

[9] Y. Yamamoto and S. M. Lakho. Proc. Japan Soc .of Civil Eingeer, 322 (1982).

[10] P.N. Chopra. Proc. on Rice Husk Ash Cement, Peshawar, Pakistan, (1979).

[11] D.J. Cook and P. Suwanvitaya. Proc. on Rice Husk Ash Cement, Peshawar, Pakistan, (1979).

[12] N.A. Moayad. Journal of Cement Composites and Lightweight Concrete, 6(1984), p. 241-248 
[13] P.K Metha. ACI SP-79 (1983).

[14] P.K Metha. Proc. Tntl. Conf. on Durability of Concrete, Chalmers University of Technology (1989).

[15] T.J. Zhao and J.Q. Zhu. Housing Materials \& Applications, 4 (1996), p.38-40.

[16] G.C Cordeiro et al. Materials and Structures, 42(2009), p. 983-992.

[17] K.Ganesan et al. Construction and Building Materials, 22 (2008), 1675-1683.

[18] A.A. Ramezanianpour, M. Mahdi khani. Journal of Civil Engineering Engineering, 7(2009), p. 83-91.

[19] W. Tangchirapat, Buranasing R, Chai J. Construction and Building Materials, 22(2008), p.1812-1819.

[20] H.B Mahmud et al. Journal of Advanced Concrete Technology, 7(1), (2009), p. 21-30.

[21] V. Sata, J.Chai, K. Kiattikomol. Construction \& Building Materials, 21(2007), p.1589-1598.

[22] M.H. Zhang. ACI Structural Journal, 93 (1996), p. 629-636.

[23] M.S. Ismail, A.M. Waliuddin. Construction and Building Materials, 10(7), (1996), p. 521-526.

[24] A. Salas. Cement and Concrete Research, 39(2009), p.773-778.

[25] K. Sakr. Journal of Materials in Civil Engineering, 18(3), (2006), p. 367-366.

[26] G.R.D. Sensal. Cement and Concrete Composites, 28 (2006), p. 158-160.

[27] M.Nehdi, J.Duquett. Cement and Concrete Research, 33(2003), p. 1203-1210.

[28] A.Gastaldini, G. Isaia, T. Hoppe, et al. Construction and Building Materials, 23(2009), p. 3411-3419.

[29] A.A. Ramezanianpour, M.M. Khani. International Journal of Civil Engineering, 7(2009), P. 83-91.

[30] Q.G. Feng. Journal of the Chinese Ceramic Society, 36 (2008), p. 136-139.

[31] D. OuYang. Industrial Construction, 33 (2003), p. 46-48.

[32] D. OuYang. CEREAL \& FEED INDUSTRY, (6), (2003), p. 40-42.

[33] D. OuYang. New Building Materials, (8), (2003), p. 7-9.

[34] D. OuYang. Journal of Agro-Environment Science, 22 (3), (2003), p. 374-375.

[35] Q.J. Yu, S.Y. Zhao and Q.G. Feng. Journal of Wuhan University of Technology, 25 (2), (2003), P. 5-19.

[36] Q.G. Feng and L.F. Yang. Journal of Wuhan University of Technology, 27 (2), (2005), p. 17-20.

[37] R. Zerbino, G. Giaccio and G.C. Isaia. Construction and Building Materials, 25 (2011), p. 371-378.

[38] S. Hesami and S. Ahmadi. Construction and Building Materials, 53 (2014), p. 680-691.

[39] Ha Thanh Le, Matthias Müller and Karsten Siewert. Materials and Design, 72 (2015), p. $51-62$.

[40] S.Q. Liang and B.C. Sun. Concrete, 232 (2), (2009), p. 73-75.

[41] C.N. Yue. Suzhou Institute of Urban Construction and Environmental Protection, 6 (4), (1993), p. 51-57.

[42] R.M. Ferraro and A. Nanni. Construction and Building Materials, 31 (2012), p. 220-225.

[43] R. KISHORE, V. BHIKSHMA and P. J. PRAKASH. The Twelfth East Asia-Pacific Conference on Structural Engineering and Construction. Procedia Engineering, 14 (2011), p. 2666-2672.

[44] R. Madandoust and M.M. Ranjbar, et al. Biosystems Engineering, 110(2011), p.144-152.

[45] R. Madandoust and R. Ghavidel. Biosystems Engineering, 116 (2013), p. 113-119.

[46] B. Chatveera and P. Lertwattanaruk. Journal of Environmental Management, 92 (2011), p. 59-66.

[47] V. Kannan and K. Ganesan. Construction and Building Materials, 51(2014), p. 225-234. 
[48] S.K. Antiohos, J.G. Tapali, et al. Construction and Building Materials, 49 (2013), 455-463.

[49] D. OuYang. Port \& Waterway Engineering, 354 (7), (2003), p. 8-10.

[50] D. OuYang. Fly Ash Comprehensive Utilization, (4), (2003), p.14-16.

[51] D. OuYang. Coal Ash China, (4), (2003), p. 8-9, 20.

[52] Xu W, Lo T, Wang W, et al. Materials, 2016, 9(3).

[53] Md. Safiuddin, J.S. West and K.A. Soudki. Construction and Building Materials, 25 (2011), p. 973-978.

[54] Y. W. Chen, P. Z. Sun. Journal of Heilongjiang Cereals and Oils and Technology, (1996), p.17-19.

[55] N.V. Tuan, G. Ye and K.V. Breugel, et al. Construction and Building Materials, 25(2011), p. 2030-2035.

[56] N.V. Tuan, G. Ye and K.V. Breugel, et al. Cement and Concrete Research, 41 (2011), p. $1104-1111$. 